\title{
Effect of laser on erythrocytes sedimentation rate and some hematological parameters
}

\author{
Eman A. Shaker* \\ NabaaA Rasheed* \\ Zainab R. Salman*
}

\author{
MBChB, PhD (Physiology) \\ MBChB, PhD (Medical Physics) \\ BSc (Medical Physics)
}

\begin{abstract}
:
Background: This study was conducted in pursuit of gaining an understand effects of the low level laser irradiation on whole blood is very essential way in revealing the mechanisms of the action of laser radiation on biological tissues.

Objective: The purpose of this study is to investigate the in vitroeffect of laser radiation on some hematological parameters and erythrocyte sedimentation rate.

Fac Med Baghdad

2017; Vol.59, No.1

Received: Dec., 2016

Accepted: Feb.,2017

Subject and Method: Blood samples were obtained from 30 healthy volunteers, each sample was divided into four new samples, one of them was considered as control while the other three were exposed to three different laser doses. Thewavelength of $532 \mathrm{~nm}$ was used for irradiation with $4 \mathrm{~mm}$ diameter beam spot on blood samples, with power density of $796.17 \mathrm{~mW} / \mathrm{cm} 2$. The irradiation times were $1.8,3.7$ and 6.2 secand so the different doses of irradiation $1.5,3$ and $5 \mathrm{~J} / \mathrm{cm} 2$, respectively.

Results: The erythrocyte sedimentation rate was measured after laser irradiation and compared with un-irradiated control sample. The results of this study showed thaterythrocyte sedimentation rate value increased significantly with a dose of $1.5 \mathrm{~J} / \mathrm{cm}^{2}$ but not with the othertwo doses' values in male persons but not in females. Moreover, the mean cell volume shows significant decrement post irradiation.

Conclusion: Laser irradiation induces physical changes in red blood cell membrane permeability and blood viscosity and consequently alters erythrocyte sedimentation rate.

Keywords: erythrocyte sedimentation rate, hematological parameters, low level laser.
\end{abstract}

\section{Introduction:}

Biostimulation possessions of laser irradiation on living organisms were found for three decades [1-4]. The inquiry of the interaction of laser radiation with biological tissues is of pronounced concernbecause itpermits notonly gainingevidence on their characteristics but also how modulating them [5]. The study of the Low Level Laser irradiation effects on whole blood is very essential way in revealing themechanisms of the action of laser radiation on biological tissues because of the diversity of bloodcells whose membranes contains lipids, sugars and proteins [6].Numerous LLL wavelengths with different power and exposure time have been consumed in blood therapy for a variety of medical applications due to its capability to modify blood rheology and enhancement of microcirculation [7]. Actually LLL therapy does not induce thermal changes for that reason; it will not cause living cell damage [8].

The erythrocyte sedimentation rate (ESR) is one of the vital rheological considerations of human blood [9]which is frequently used to screen for presence of inflammation. It is referred to as the ESR because itmeasures the rate at which red blood cells (RBCs) separate from the liquid part of blood (plasma) and fall to the bottom of a test tube forming sediment.

The ESR is affected by two major factors; biological factors and non- biological factors.Biological factors include the

*Department of physiology, college of medicine, university of AlMustansirya., Corresponding Email:zainabraad@gmail.com erythrocyte factor, the plasma, theviscosity factor, the age, gender and the race factors. Thenon- biological factors include technical factors, physical factors such as the effect of laser radiation and some of the mechanical factors[10].In this study, we have intended to clear up the impact of different LLL doses at wavelength of $532 \mathrm{~nm}$ on the rheological parameter (ESR) of human blood and red blood cell (RBC), mean cell hemoglobin concentration (MCHC),red blood distribution width (RDW), hemoglobin $(\mathrm{Hb})$ and mean cell volume(MCV).

\section{Materials and Method:}

Blood sample: The blood samples were collected fromthirty apparently healthy individuals (18 males and 12females, mean age $26.966 \pm 5.009)$ with no history ofchief illnesses or irregular medications. They wereinstructed about the purpose of the study andverbal permissionwas taken from all participants. About $10 \mathrm{ml}$ of blood were collected through venipuncturein ethylene diamine tetra acetic acid (EDTA)-containing tubes $(1.3 \mathrm{mg} / \mathrm{ml}$ of blood) as an anticoagulant. The samples were then managed instantly aftercollection. Each sample was apportioned into four equal aliquots, oneto be used as nonirradiated sample (control) and the other three were exposed to different laser doses using a continuous ND: YAG laser.

Laser specification: In this study, a diode laser pointer was used as irradiation source with a wavelength of $532 \mathrm{~nm}$, and a low power of $100 \mathrm{~mW}$ in a continuous wave mode. The divergence was $<1.5 \mathrm{mRad}$. The crystal type of this source was Nd: VYO4: 
KTP. The laser spot diameter was $0.4 \mathrm{~cm}$. The power density was $796.17 \mathrm{~m} \mathrm{~W} / \mathrm{cm}^{2}$.Sample irradiation: The blood samples of $2.5 \mathrm{ml}$ per tube were irradiatedwith a laser beam of $0.4 \mathrm{~cm}$ spot diameter. The delivered dose for each irradiated set was $1.5,3$ and $5 \mathrm{~J} / \mathrm{cm}^{2}$, at different exposure time; $1.8,3.7$ and 6.2 seconds,respectively. The laser beam was focusedroutinely to the center of the blood containing test tube. Theirradiation process was achieved at room temperature $\left(18-25^{\circ} \mathrm{C}\right)$. Blood analysis: Complete blood picture including ( $\mathrm{RBC}, \mathrm{RDW}, \mathrm{Hb}$, MCV and MCHC) were measured automatically by using a hematology analyzer machine (Swelab Alfa Standard/ Sweden) standard westergren method were used to evaluated ESR level. All tests were achievedatthe National Center of Hematology (Specialty Center for Blood Diseases).

Statistical evaluation: The data is assessed by the use of Excel software; the values are expressed as mean \pm standard deviation. The differences between the three irradiated and controlsamples were estimated by applying a paired t test. The $\mathrm{P}$ value is determined according to the analysis of the significance of the difference. The $\mathrm{P}$ value less than 0.05 are considered significant.

\section{Results:}

Impact on hematological parameters at different laser doses:Table-1 shows the response of blood parameters to different laser doses, of which only theMCV shows significant differences in response to laser irradiation.

\section{ESR at different low level laser}

Erythrocyte sedimentation rate is one of non- specific investigations that could be modulated by different factors. As there was a significant normal physiological difference in ESR with regards to gender (proved in this study $\mathrm{P}<0.0001$, unpaired T-test), we checked the effects of laser irradiation separately. Interestingly, they behaved in different way. ESR value was increased significantly with first dose $1.5 \mathrm{~J} / \mathrm{cm}^{2}$ but not with others and in male persons not in females $(\mathrm{P}<0.04)$ (Figure.1).

Table (1): The response of some hematological parameters to different laser doses compared to control

\begin{tabular}{|c|c|c|c|c|c|c|c|}
\hline Parameter & Pre-irradiation(control) & $1.5 \mathrm{j} / \mathrm{cm}^{2}$ & P value & $3 \mathrm{j} / \mathrm{cm}^{2}$ & P value & $5 \mathrm{j} / \mathrm{cm}^{2}$ & Pvalue \\
\hline RBC & $4.96 \pm 0.41$ & $4.94 \pm 0.43$ & 0.32 & $4.93 \pm 0.43$ & 0.25 & $4.92 \pm 0.38$ & 0.22 \\
\hline МCHC & $32.86 \pm 1.71$ & $32.91 \pm 1.44$ & 0.34 & $32.98 \pm 1.53$ & 0.14 & $32.99 \pm 1.34$ & 0.14 \\
\hline RDW & $11.73 \pm 0.61$ & $11.74 \pm 0.66$ & 0.41 & $11.73 \pm 0.70$ & 0.43 & $11.72 \pm 0.65$ & 0.44 \\
\hline $\mathbf{H b}$ & $14.06 \pm 1.43$ & $13.97 \pm 1.37$ & 0.24 & $13.98 \pm 1.36$ & 0.25 & $13.97 \pm 1.30$ & 0.23 \\
\hline MCV & $86.49 \pm 4.89$ & $86.28 \pm 4.77$ & 0.02 & $86.18 \pm 4.80$ & 0.003 & $86.13 \pm 4.85$ & 0.001 \\
\hline
\end{tabular}

Table 2: The impact of different laser doses on ESR value in different gender compared with control group

\begin{tabular}{cccccccc}
\hline ESR $(\mathrm{mm} / \mathrm{h})$ & Pre-irradiation(control) & $* 1.5 \mathrm{~J} / \mathrm{cm}^{2}$ & P value & $* 3 \mathrm{~J} / \mathrm{cm}^{2}$ & P value & $* 5 \mathrm{~J} / \mathrm{cm}^{2}$ & $\mathrm{P}_{\text {value }}$ \\
\hline FemaleNO=12 & $18.3 \pm 4.7$ & $18.7 \pm 6.2$ & 0.35 & $18.7 \pm 6.0$ & 0.25 & $21.5 \pm 6.4$ & 0.11 \\
\hline MaleNO=18 & $4.1 \pm 2.2$ & $4.6 \pm 2.7$ & 0.04 & $4.5 \pm 2.8$ & 0.09 & $4.5 \pm 3.1$ & 0.18 \\
\hline Male/FemaleP $=$ & 0.0001 & & & & & &
\end{tabular}

* results are expressed as mean $\pm \mathrm{SD}$.

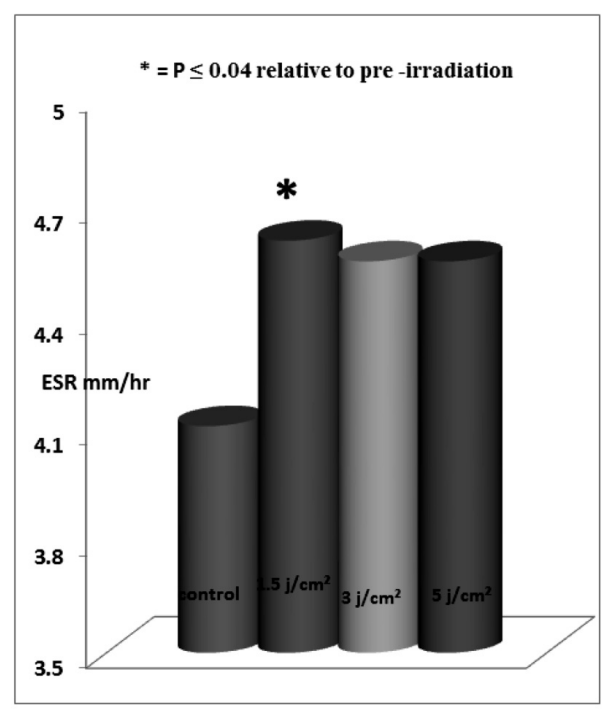

Figure1: ESR changes in response to different laser doses in male person.

\section{Discussion:}

This is a comparative experimental study in which the effects of thethree different laser doses upon ESR value were evaluated. Since there was a significant physiological difference in ESR with regards to gender, the impact of laser irradiation were tested separately. An interesting observation was found in form of increasing ESR in male person post irradiation with $1.5 \mathrm{~J} / \mathrm{cm}^{2}$ but not in female. The definite reason behind this gender divergence in response to laser irradiation is unclear. Nevertheless, it might be due to differences in sample size (females were $2 / 3$ of male number). Though, laser irradiation induces physical changes within limited range which is not obvious in higher ESR value as in female could be one of the explanation. Additionally, it was determined that, laser irradiation decreases blood viscosity thus increasing the electrophoretic mobility of RBC [11]. Consequently, decreasing blood viscosity plays mandatory role in elevating ESR value. Several studies were in alignment with our observation[10, 12,13] while another study did not [14].The potential reason 
for decreasing of whole blood viscosity is either decline in concentration of erythrocytes per unit volume (hematocrit) value(which is not reported in our study since the RBC count unchanged post irradiation), or change in volume and shape of $\mathrm{RBC}$ [13]. Alteration in volume of the RBC had been detected in ourstudy. Moreover, higher doses of laser failed to induce apparent changes in ESR value in spite of its recognizable influence on MCV (table 1), this may indicate that at this dose it reaches the threshold level and the bio-stimulation is replaced by bio-inhibition [15].However, the outer possible important ESR should not be neglected, like plasma proteins including fibrinogen and globulin. Previously reported that He-Ne laser $(638.2 \mathrm{~nm})$ seems to change the charges in plasmaproteins with dose and incubation time after irradiation [16]. Unfortunately, this factor would not estimated in this work; hopefully it will be done in future work.

\section{Conclusion:}

Laser irradiation induces physical changes in $\mathrm{RBC}$ membrane permeability and MCV which in turn modulate blood viscosity and consequently alters ESR.

\section{References:}

[1] Mester E., Mester A.F. and Mester A.The Biomedical Effects of Laser Application. Lasers in Surgery andMedicine, 1985; 5: 31-39.

[2] BasfordJ.R. Low Intensity Laser Therapy: Still Not an Established Clinical Tool. Lasers in Surgery and Medicine, 1995; 16: 331-342.

[3] Lubart R., Wollman Y., Friedmann H., Rochkind S. and Laulicht I. Effects of Visible and Infrared Lasers onCell Cultures. Journal of Photochemistry and Photobiology B, 1992; 12:305-310.

[4] Sroka R., Schaffer M., Fuchs C., Pongartz T., SchraderReichard U., Busch M., Schaffer P.M., Duhmke E. andBaumgartner R. Effect on Mitosis of Normal and Tumor Cells Induced by Light Treatment of Different Wavelength. Lasers in Surgery and Medicine, 1999; 25: 263-271.

[5] SturessonC. and Andersson-Engels. Increase the Depth of Selective Damage to Blood Vessels in Laser Treatment of Port Wine Stains. Physics in Medicineand Biology, 1996; 41: 413428

[6] Brill G.E.Molecular-Cellular Basis of the Therapeutic Action of Low-Intensity Laser Radiation. DidacticTextbook. Medical University, Saratov (Russia), 2000.

[7]Yinghua $C$, Wenming X. Mechanism analysis on ILIB improvingthe property of rheology of blood. Laser J,2002; 2: 30 .

[8 JVladimirov YA, Osipov AKlebanovG. Photobiologicalprinciples of therapeutic applications of laser radiation. Biochemistry (Moscow), 2004; 69:81-90.

[9]Lin'kova N, Gorshkova O, Shuvaeva V, Dvoretskii D. Effectof low-intensity laser radiation of the red spectrum on some propertiesof erythrocytes inWistar rats. Bull ExpBiol Med, 2008;145:7-9.

[10] Ibrahim Ahmed A.The Effect Of Laser Radiation And
Viscosity Of Red Blood Cells On Erythrocytes Sedimentation Rate (ESR).Tikrit Journal of Pure Science, Kirkuk: physics Department, Science College, University of Kirkuk 2010; 15 : $75-83$

[11] Al Timimi Zahra, Jaafar M.S. and Jafri Mohd Zubir Mat. Photodynamic therapy and Green Laser blood Therapy - Penang, Malaysia: Global Journals Inc. (USA), 2011; 11: 23-27.

[12]Rathore Shikha and Ali Basharath. EFFECT OF LASER RADIATION ON ELECTRICAL CONDUCTIVITY OF HUMAN BLOOD. - India : International Journal of Science, Environment and Technology, 2014; 3: 286-290.

[13]Rathore Shikha and Ali Basharath. Effect of He-Ne laser radiation on viscometric behavior of Human blood. - india: Journal of chemical, Biological and physical sciences, 2013; 3:2124-2129.

[14] Al Musawi Mustafa.S., Mohamad Suhaimi Jafar, Bassam T. Al-Gailani, Naser Mahmoud Ahmed, Fatanah Mohamad Suhaimi, and Nursakinah Suardi. In Vitro Mean Red Blood Cell Volume Change Induced by Diode Pump Solid State LowLevel Laser of $405 \mathrm{~nm}$. Photomed Laser Surg, 2016; 5: 211214

[15] Huang Y-Y, Chen AC-H, Carroll JD, Hamblin MR. Biphasicdose response in low level light therapy. DoseResponse, 2009; 7: 09-27.

[16] Genkin V, Novikov V, Paramonov L, El'kina B. Effects oflow-intensity laser irradiation on the state of blood proteins. Biulleten'eksperimental'noibiologiiimeditsiny, 1989; 8:188190. 